\title{
Head and neck cancer in HIV patients and their parents: a Danish cohort study
}

This article was published in the following Dove Press journal:

Clinical Epidemiology

20 July $201 \mathrm{I}$

Number of times this article has been viewed

\section{Frederik N Engsig' \\ Jan Gerstoft ${ }^{\prime}$ \\ Gitte Kronborg ${ }^{2}$ \\ Carsten S Larsen ${ }^{3}$ \\ Gitte Pedersen ${ }^{4}$ \\ Court Pedersen ${ }^{5}$ \\ Niels Obel'}

'Department of Infectious Diseases, Copenhagen University Hospital,

Rigshospitalet, Denmark; '2Department of Infectious Diseases, Copenhagen

University Hospital, Hvidovre,

Denmark; ${ }^{3}$ Department of Infectious

Diseases, Aarhus University Hospital,

Aarhus, Denmark; ${ }^{4}$ Department

of Infectious Diseases, Aalborg

University Hospital, Aalborg,

Denmark; ${ }^{5}$ Department of Infectious

Diseases, Odense University Hospital,

Odense, Denmark
Correspondence: Frederik Neess Engsig

Department of Infectious Diseases,

Rigshospitalet, Blegdamsvej 9,

DK2 100 Copenhagen $\varnothing$, Denmark

Tel +4635457726

Fax +4535456648

Email fren74@gmail.com
Background: The mechanism for the increased risk of head and neck cancer (HNC) observed in HIV patients is controversial. We hypothesized that family-related risk factors increase the risk of HNC why we estimated the risk of this type of cancer in both HIV patients and their parents.

Methods: We estimated the cumulative incidence and incidence rate ratios (IRRs) of HNC in 1) a population of all Danish HIV patients identified from the Danish HIV Cohort Study $(n=5053)$ and a cohort of population controls matched on age and gender $(n=50,530)$ (study period; 1995-2009) and 2) the parents of HIV patients and population controls (study period 1978-2009). To assess the possible impact of human papilloma virus (HPV)-associated cancers, the sites of squamous cell HNCs were categorized as HPV related, potentially HPV related, and potentially HPV unrelated.

Results: Seventeen $(0.3 \%)$ HIV patients vs $80(0.2 \%)$ population controls were diagnosed with HNC cancer in the observation period. HIV patients had an increased risk of HNC (IRR 3.05 [95\% CI 1.81-5.15]). The IRR was considerably increased in HIV patients older than 50 years (adjusted IRR; 4.58 [95\% CI 2.24-9.35]), diagnosed after 1995 (adjusted IRR 6.31 [95\% CI 2.82-14.08]), previous or current smoker (adjusted IRR 4.51 [95\% CI 2.47-8.23]), with baseline CD4 count 350 cells/ $\mu \mathrm{L}$ (adjusted IRR; 3.89 [95\% CI 1.95-7.78]), and men heterosexually infected with HIV (adjusted IRR 5.54 [95\% CI 1.96-15.66]). Fifteen (83\%) of the HIV patients diagnosed with HNC were current or former smokers. The IRR of squamous cell HNC in HIV patients was high at HPV-relate sites, potentially HPV-related sites, and potentially HPV-unrelated sites. Both fathers and mothers of HIV patients had an increased risk of HNC (adjusted IRR for fathers 1.78 [95\% CI 1.28-2.48], adjusted IRR for mothers 2.07 [95\% CI 1.05-4.09]).

Conclusion: HIV appears to be a marker of behavioral or family-related risk factors that affect the incidence of HNC in HIV patients.

Keywords: HIV, head and neck cancer incidence, matched cohort, population controls, parents

\section{Introduction}

After the introduction of highly active antiretroviral therapy (HAART) HIV has changed from a fatal disease to a chronic condition and well-treated HIV patients now have an overall life expectancy close to that of non-HIV patients. ${ }^{1}$ Due to immunological recovery, there has been a remarkable decline in AIDS-defining cancers, whereas the increased risk of certain non-AIDS-defining cancers, including head and neck cancer (HNC), has persisted in the HIV population. ${ }^{2-5}$ Besides alcohol consumption and smoking, risk of $\mathrm{HNC}$ has been associated with infection with human papilloma virus (HPV). ${ }^{6-10}$ The 
exact mechanism behind the increased risk of HNC in HIV patients is unclear.

We hypothesized that family-related risk factors may partly explain the increased risk of HNC observed in HIV patients. We therefore performed a national cohort study to compare the risk of HNC in Danish HIV patients and their parents with that of matched cohorts from the background population.

\section{Methods}

In this study we estimate the risk of HNC in 1) HIV patients compared with population controls matched on age and gender and 2) in the parents of the HIV patients compared with the parents of the population controls.

\section{Setting}

Denmark had a population of 5.5 million as of 31 December 2008, with an estimated HIV prevalence of approximately $0.09 \%$ in the adult population.

\section{Data sources}

We used the unique 10-digit civil registration number assigned to all individuals in Denmark at birth or on immigration to link the data sources described below. ${ }^{11}$

The Danish HIV Cohort study (DHCS) is a populationbased prospective nationwide cohort study of all HIV patients 16 years or older at diagnosis and who are treated at Danish HIV centers after 1 January 1995. Patients are consecutively enrolled, and multiple registrations are avoided through the use of the unique civil registration number. Data are updated yearly and include demographics, data on smoking, date of HIV infection, route of HIV infection, AIDS-defining events, date and cause of death, and antiretroviral treatment. CD4 ${ }^{+}$ cell counts and HIV-RNA measurements are extracted electronically from laboratory data files. The study is described in detail elsewhere. ${ }^{12}$ Patients who were registered at least once as consuming tobacco in any quantity were considered smokers.

Population controls and parents of both HIV patients and population controls were identified from the Danish Civil Registration System (DCRS). The DCRS was established in 1968 and stores information of vital status, residency as well as immigration and emigration on all Danish residents. ${ }^{11}$

Data on all cancers were obtained from the Danish Cancer Registry. The Danish Cancer Register is a population-based register and contains information on all incident cancers diagnosed in Danish Citizens since 1943. ${ }^{13}$
Data on smoking are not available in the Danish national registries.

\section{Study populations \\ HIV and population controls}

In the first part of the study, we included all HIV patients from the Danish HIV Cohort Study assigned a Danish civil registration number and not diagnosis with cancer prior to index date (see Figure 1). The index date was defined as 1 January 1995, the date of the HIV diagnosis, or date of immigration, whichever came last. For each of the HIV patients we identified 10 age- and gender-matched population control subjects from the DCRS who were alive and living in Denmark at the index date of the corresponding HIV patient (referred to also as the index date of the respective population controls) and not diagnosed with a cancer prior to index date.

\section{Parents}

Over time, inclusion of parents' civil registration numbers in the DCRS has increased from $<10 \%$ for individuals born before 1952 , to $43 \%$ for the 1952 birth cohort, to $96 \%$ for the 1959 birth cohort, and to $99 \%$ for persons born after $1970 .{ }^{14}$ Consistent with this trend, we found that $8 \%$ of individuals born before 1952 had registered parents. HNCs have been classified by both topography and histological type since 1978. Thus, to reduce selection bias we included parents of HIV patients/population controls who 1) gave birth to an HIV patient/population control individual after 1 January 1952, 2) were alive and living in Denmark after 1 January 1978, 3 ) were not diagnosed with cancer prior to the parent index date, and 4) reached the age of 40 years in the study period (see Figure 1). In order to make the parent populations more homogenous in terms of age and risk, observation did not start until date of the fortieth birthday. In summary, the parent index date was defined as 1 January 1978, date of birth of the included HIV patient or population control, the date of the fortieth birthday, or date of registration in DCRS, whichever came last. In case a parent was the father or mother of both an HIV patient and a population control, they were included in both parent populations.

\section{Outcome}

In the first study, outcome was time to first diagnosis of HNC. All primary cancers were identified using NORDCAN definitions $^{15}$ (see Appendix). HNC was defined as the following ICD-10 codes: C00-C14, C30-C32. Lymphomas and nonmicroscopically confirmed malignancies in the head 


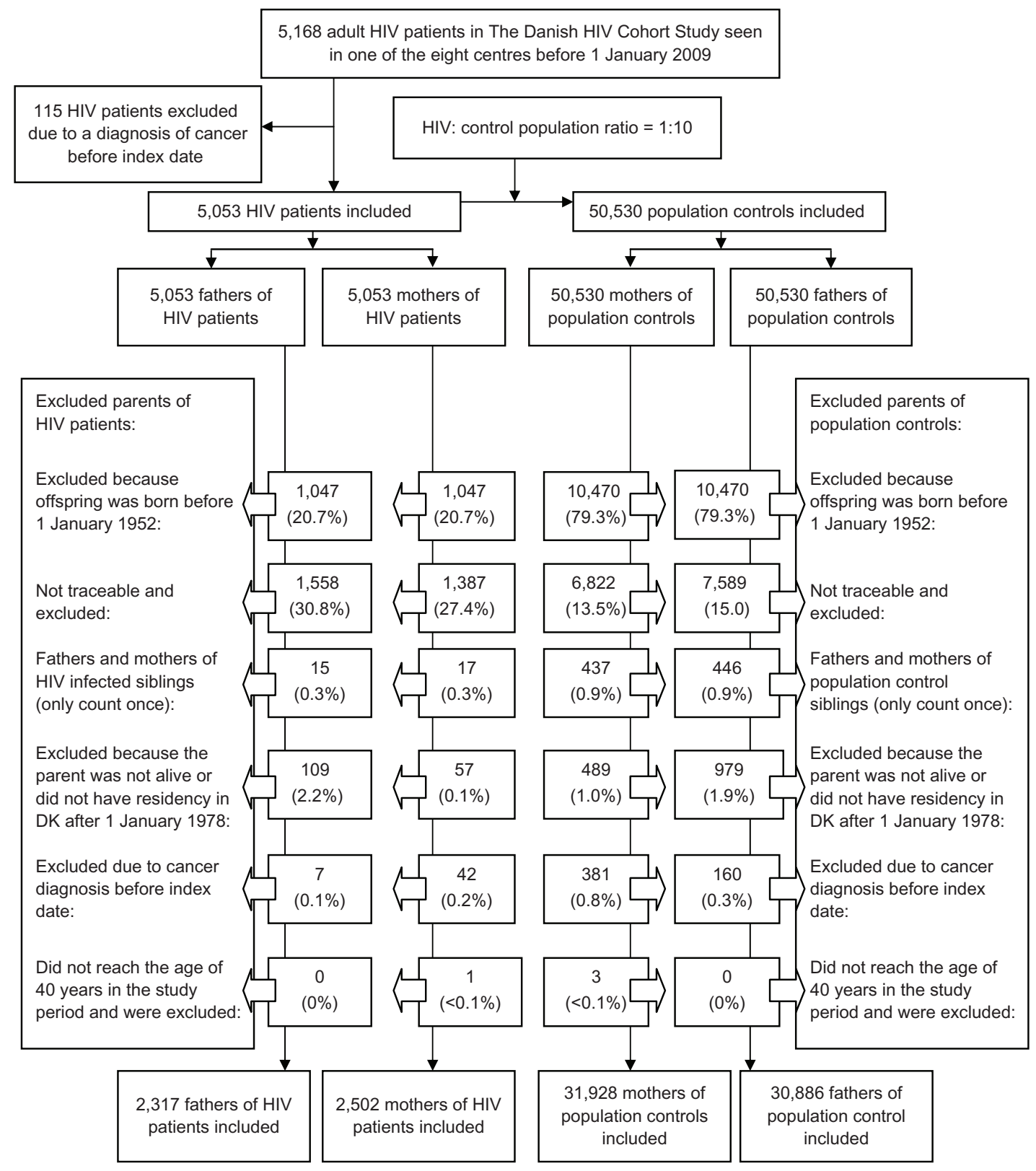

Figure I Summary of the study design.

neck region were not considered HNCs. Further, we divided all HNCs of squamous cell origin (ICD-O-3 morphology codes 8050-8084, 8120-8131) into three groups: HPV related, potentially HPV related, and potentially HPV unrelated. The three groups are based on the classification made by Ryerson et $\mathrm{al}^{16}$ and categorized by the following ICD-1O codes - 1) HPV-associated: Tonsils including Waldeyers ring $(\mathrm{C} 09, \mathrm{C} 14.2)$, Base of tongue and lingual tonsil (C01.9, C02.4), Other oro-pharyngeal sites (C02.8, C10.2, C10.8.0, C10.9, C14.0, C14.8); 2) Potentially HPV-associated: Tongue (C02.0- $\mathrm{C} 02.3, \mathrm{C} 02.9)$, Other oral cavity sites ( $\mathrm{C} 03$, C04, C05.0, C06), Larynx (C32), Other oro-pharyngeal sites (C05.1, C05.2, C05.8, C05.9, C10.0, C10.1, C10.3); and 3) Potentially unrelated to HPV: Remaining HNC sites (C00, C07, C08, C10.4, C11-C13, C14.1, C30, C31). The potentially HPV-related cancers are based on the anatomical similarity to the HPV-related cancers in the first group, even though an association with HPV has not yet been established.

\section{Statistics}

Differences in characteristics between groups were evaluated by the $\chi^{2}$ test/Fischer's exact test and Kruskal-Wallis test when appropriate. 
We estimated the probability of $\mathrm{HNC}$ and the relative risk of $\mathrm{HNC}$ in all study populations. Observation time was calculated from the respective index date to date of diagnosis of $\mathrm{HNC}$ or other cancers, death, 1 January 2009, emigration, or lost to follow-up, whichever came first. We used cumulative incidence function to illustrate time to first $\mathrm{HNC}$, recognizing death and diagnoses of other cancers as a competing risk. ${ }^{17}$ Incidence rate ratios (IRR) and 95\% confidence intervals (CI) for $\mathrm{HNC}$ were calculated using Cox proportional-hazards regression.

In order to identify risk factors for HNC in the HIV patient population, we calculated IRRs stratified by gender, race (Caucasian vs non-Caucasian), age at index date ( $\leq 50$ years vs $>50$ years), diagnosis of HIV before 1 January 1995 , smoking (previous or current smoker in any quantity, never smoked, unknown smoking status), route of infection (men who have sex with men [MSM], heterosexually infected men and women, injection drug user [IDU]), AIDS-defining event at index date or prior to 1 January 1995 if diagnosed with HIV before 1 January 1995 (none vs $\geq$ one) or low baseline CD 4 cell count $(<350$ cells $/ \mu \mathrm{L}$ vs $\geq 350$ cells $/ \mu \mathrm{L}$ ). IRRs were calculated for both HNC cancers of squamous cell and other origin as well as for the HPV-related cancers, the potentially HPV-related cancers, and the potentially HPV-unrelated cancers. All results were adjusted for age (continuous variable) and gender. We calculated overall IRRs of HNC in the parent populations and IRRs stratified on the HIV infected offspring's route of infection. IRRs for parent populations were adjusted for age at parent index date (continuous variable) as well as year of birth of the parent divided into the following decades: 1920, 1920-1930, 1930-1940, 1940-1950, 1950 - later.

The study was approved by the Danish Data Protection Agency. SPSS statistical software, Version 15.0 (Norusis; SPSS Inc., Chicago, Illinois, USA) and R software, version 2.8.1, was used for data analysis.

\section{Results}

In the first part of the study, we included a total of 5053 Danish HIV patients and 50,530 age- and gender-matched population controls with a total of 37,622 and 470,322 person-years of follow-up (Figure 1). Patient characteristics are described in Table 1.

A total of 333 (6.6\%) HIV patients and 1328 (2.6\%) population controls were diagnosed with a cancer in the observation period and 25 and 83, respectively, were diagnosed with HNC. Among these HNCs we excluded seven lymphomas and one nonmicroscopically confirmed cancer in the HIV patients and one lymphoma and two nonmicroscopically confirmed cancer in the population controls, leaving a total of $17(0.3 \%)$ and
$80(0.2 \%)$ HNCs. Their characteristics are listed in Table 1. Fifteen (83\%) HIV patients with HNC were smokers. Nadir CD4 cell count in the HIV patients diagnosed with HNC was 180 cells $/ \mu \mathrm{L}$ (interquartile range [IQR] 36-253 cells $/ \mu \mathrm{L}$ ) and median CD4 cell count at time of cancer diagnosis was 408 cells $/ \mu \mathrm{L}$ (IQR $280-628$ cells $/ \mu \mathrm{L}$ ).

As seen in Figure 2, the HIV patients had a $>$ three times higher 10-year probability for HNC than the control population. The IRR of HNC was three times higher for HIV patients (adjusted IRR 3.05 [95\% CI 1.81-5.15]). The IRRs for HNC remained high in all stratified analyses (Table 2). The risk of HNC according to HPV-related sites differed little (Table 2).

We identified a total of 2317 fathers of HIV patients, 30,886 fathers of population controls, 2502 mothers of HIV patients, and 31,928 mothers of population controls (Table 3). The 20-year probability of HNC was higher for both fathers and mothers of HIV patients (Figure 3A, B). The adjusted IRR for $\mathrm{HNC}$ for fathers and mothers of HIV patients were 1.78 (95\% CI 1.28-2.48) and 2.43 (95\% CI 1.51-3.92). After stratification on the children's route of HIV infection, the relative risk remained high in all groups particularly for parents of MSMs (Table 4).

\section{Discussion}

We found a threefold increased risk of HNC in HIV patients compared with the background population. None of our stratified analyses identified a single risk factor which could explain the increased incidence of HNC in this patient population. Both fathers and mothers of HIV patients had an increased risk of HNC compared with the parents of the population controls. HIV appeared to be a marker of family-related factors that affect the risk of HNC.

To our knowledge this is the first nationwide study comparing the incidence of HNC in HIV patients with that of a matched control population and their parents. A major strength of the study is the quality and coverage of the Danish registries and the population-based design with long and nearly complete follow-up along with access to valid data on family members. Further we included only microscopically confirmed HNCs, thereby eliminating the risk of misclassification.

We did not estimate the risk of $\mathrm{HNC}$ in relation to the implementation of HAART. However, the development of HNC presumably takes several years and it is therefore difficult to estimate the impact of risk factors that vary over time. Our registry data did not allow adjustment for 
Table I Characteristics of HIV patients and population controls with head and neck cancer

\begin{tabular}{|c|c|c|c|c|c|}
\hline & $\begin{array}{l}\text { HIV patients, } \\
\text { N (\%) }\end{array}$ & $\begin{array}{l}\text { Population } \\
\text { controls, } \\
\text { N (\%) }\end{array}$ & $\begin{array}{l}\text { HIV patients diagnosed } \\
\text { with head and } \\
\text { neck cancer, } N(\%)\end{array}$ & $\begin{array}{l}\text { Population controls } \\
\text { diagnosed with head } \\
\text { and neck cancer, } \mathrm{N}(\%)\end{array}$ & $P$ value* \\
\hline $\bar{N}$ & 5053 & 50,530 & 17 & 80 & \\
\hline Male gender & 3827 (75.7) & $38,270(75.7)$ & $13(76)$ & $77(95)$ & 0.004 \\
\hline $\begin{array}{l}\text { Age at time of index date, } \\
\text { median (IQR), years }\end{array}$ & $36.6(30.4-44.3)$ & $36.6(30.4-44.3)$ & $50.90(40.23-54.49)$ & $47.18(40.32-56.06)$ & 0.809 \\
\hline $\begin{array}{l}\text { Age at time of cancer } \\
\text { diagnosis, median (IQR), years }\end{array}$ & - & - & $55.58(48.62-61.90)$ & $55.03(48.63-62.54)$ & 0.802 \\
\hline $\begin{array}{l}\text { Older than } 50 \text { years } \\
\text { at index date }\end{array}$ & $695(13.8)$ & $6950(13.8)$ & $10(59.0)$ & $31(38.8)$ & 0.128 \\
\hline Caucasians & 3976 (78.7) & & $16(94.0)$ & & \\
\hline \multicolumn{6}{|l|}{ Route of HIV infection } \\
\hline Men who have sex with men & $2287(45.3)$ & & $6(35.0)$ & & \\
\hline Heterosexually infected & I864 (36.9) & & $6(35.0)$ & & \\
\hline Injection drug user & $553(10.9)$ & & $3(17.6)$ & & \\
\hline Other & $349(6.9)$ & & $2(11.8)$ & & \\
\hline $\begin{array}{l}\text { One or more AIDS defining } \\
\text { events prior to index date }\end{array}$ & $719(14.2)$ & & $3(17.6)$ & & \\
\hline Diagnosed with HIV before & 1968 (38.9) & & $8(47.1)$ & & \\
\hline I January 1995 & & & & & \\
\hline Current or previous smoker** & $2600(71.1)$ & & $15(88.2)$ & & \\
\hline Never smoked ${ }^{* * *}$ & $1058(28.9)$ & & $2(11.8)$ & & \\
\hline Unknown smoking status & I395 (27.6) & & - & & \\
\hline \multirow{2}{*}{$\begin{array}{l}\text { Baseline CD4 cell count, } \\
\text { cells/ } \mu \mathrm{L}, \text { median (IQR) }\end{array}$} & $279(104-480)$ & & $309(30-402)$ & & \\
\hline & & & $\begin{array}{l}\text { HIV patients with head } \\
\text { and neck cancer, } \mathrm{N}(\%)\end{array}$ & $\begin{array}{l}\text { Population controls with } \\
\text { head and neck cancer, } \mathrm{N}(\%)\end{array}$ & \\
\hline $\begin{array}{l}\text { All head and neck cancers } \\
\text { of squamous cell origin }\end{array}$ & & & $16(100)$ & $70(100)$ & \\
\hline HPV sites & & & $6(37.5)$ & $16(22.9)$ & \\
\hline Tonsil and Waldeyers ring & & & $3(50.0)$ & $12(75.0)$ & \\
\hline Tongue base and tonsil & & & I (I6.7) & I (6.3) & \\
\hline Other oro-pharynx & & & $2(33.3)$ & $3(18.8)$ & \\
\hline Potential HPV sites & & & $7(43.8)$ & $42(60.0)$ & \\
\hline Tongue & & & I (I4.3) & $4(9.5)$ & \\
\hline Other oral cavity sites & & & I (I4.3) & $14(33.3)$ & \\
\hline Larynx & & & $5(7 \mid .4)$ & $22(52.4)$ & \\
\hline Other oro-pharyngeal sites & & & $0(0)$ & $2(4.8)$ & \\
\hline Potentially unrelated to HPV & & & $3(18.8)$ & $12(17.1)$ & \\
\hline Remaining $\mathrm{HNC}$ sites & & & $3(18.8)$ & $12(17.1)$ & \\
\hline $\begin{array}{l}P \text { value for difference in } \\
\text { distribution of HPV site, } \\
\text { potential HPV site and } \\
\text { potentially unrelated HPV site }\end{array}$ & & & & & 0.424 \\
\hline
\end{tabular}

Note: $* P$ value for differences between HIV patients diagnosed with head and neck cancer and population controls diagnosed with head and neck cancer. $* * 2600 \mathrm{HIV}$ patients were current or previous smokers out of 3658 HIV patients asked about smoking. *** 058 HIV patients had never smoked out of 3658 HIV patients asked about smoking. Abbreviations: HPV, human papilloma virus; IQR, interquartile range.

potential effects of confounders, such as smoking and alcohol consumption, and we had no data on HPV prevalence status or HPV status of the tumors. The few number of events did not allow us to perform complex multivariate analyses which is why we chose to use a stratified approach adjusted only for age and gender.

The epidemiology of HNC has changed during the last 40 years in the Western world. There has been an increase in the incidence rates of squamous cell HNCs at HPV-related and potentially HPV-related sites especially seen in men $<60$ years, whereas the incidence rates of HNC at potentially HPV-unrelated sites have been stable. ${ }^{16,18}$ The increase in HNC is seen in spite of unchanged alcohol consumption rates, increased vegetable and fruit intake, and a decreasing prevalence of smoking in the same period. ${ }^{19}$ These findings suggest that other etiological factors are involved. 


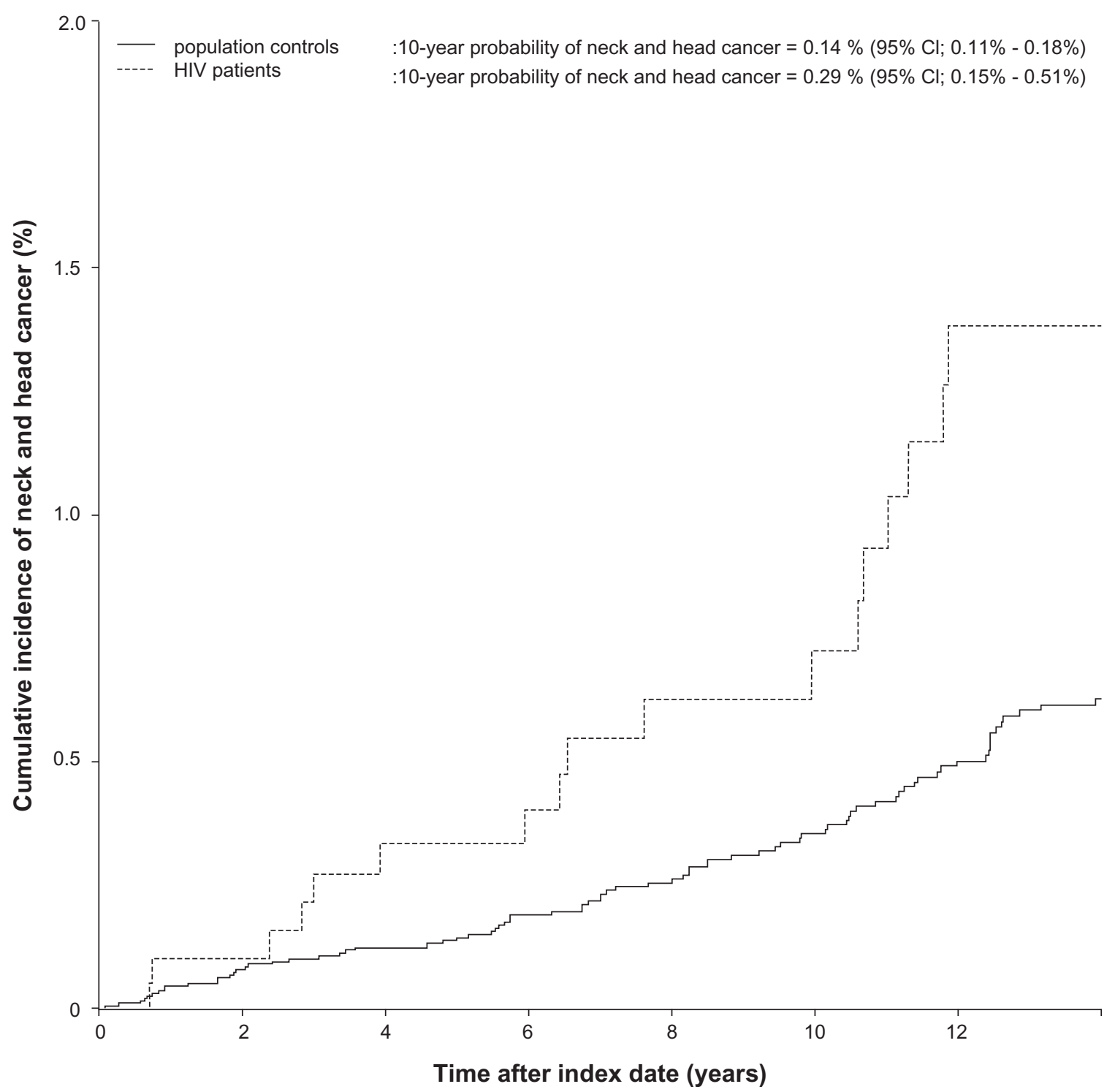

Figure 2 Cumulative incidence function for head and neck cancer among HIV patients and population controls. Abbreviation: $\mathrm{Cl}$, confidence interval.

A high prevalence of HPV DNA has been demonstrated in certain HNC tumors and high-risk types of HPV have been reported to be risk factors for several types of HNCs, perhaps due to changes in sexual behavior especially oral sex in the younger generations. ${ }^{20-23}$ Also, the prognosis is more favorable in HPV-positive HNCs, pointing towards a different type of $\mathrm{HNC}$ than those related to alcohol and tobacco consumption. ${ }^{24,25}$

We found an excess risk of HNC in Danish HIV patients which is consistent with the findings of Silverberg et al who reported a relative risk of 2.0 for HPV-related HNCs and 2.7 for other HNCs in HIV patients. ${ }^{4}$ The relative risk of HNC was also high in younger HIV patients which is probably confounded by the larger prevalence of smoking compared with the background population. Also HIV patients diagnosed after 1995 were at higher risk. The reason could be that this patient group has a smaller degree of immunodeficiency and competing HIV-related comorbidity due to larger availability of HAART, thereby allowing for the development of cancers that are more directly related to life style than immunodeficiency. More than $70 \%$ of the HIV patients were previous or current smokers and this group of HIV patients had an increased risk of $\mathrm{HNC}$.

Studies investigating the association between $\mathrm{HNC}$ and sexual behaviors in persons without HIV found an increased risk of $\mathrm{HNC}$ in tonsils and base of tongue in gay men, possibly related to differences in sexual practices. ${ }^{26}$ In contrast, the 
Table 2 Stratified incidence rate ratios (IRRs) of head and neck cancer in HIV patients compared with population controls

\begin{tabular}{|c|c|c|c|c|}
\hline & $\begin{array}{l}\text { HIV patients diagnosed } \\
\text { with head and } \\
\text { neck cancer, } \mathrm{N}\end{array}$ & $\begin{array}{l}\text { Population controls } \\
\text { diagnosed with head } \\
\text { and neck cancer, } \mathbf{N}\end{array}$ & $\begin{array}{l}\text { Unadjusted IRR } \\
(95 \% \mathrm{CI})\end{array}$ & $\begin{array}{l}\text { Adjusted IRR** } \\
(95 \% \mathrm{CI})\end{array}$ \\
\hline All & 17 & 80 & $2.76(1.64-4.67)$ & $3.05(1.81-5.15)$ \\
\hline \multicolumn{5}{|l|}{ Stratified on risk factors* } \\
\hline Male gender** & 13 & 77 & $2.26(1.25-4.07)$ & $2.47(1.37-4.45)$ \\
\hline Female gender & 4 & 3 & $15.76(3.52-70.58)$ & $* * *$ \\
\hline Caucasian & 16 & 76 & $2.80(1.63-4.80)$ & $3.05(1.78-5.23)$ \\
\hline Non-Caucasians & 1 & 4 & $2.92(0.33-26.13)$ & $* * *$ \\
\hline Younger than or 50 years at index date & 7 & 49 & $1.89(0.85-4.17)$ & $1.92(0.87-4.23)$ \\
\hline Older than 50 years at index date** & 10 & 31 & $4.50(2.21-9.20)$ & $4.58(2.24-9.35)$ \\
\hline HIV diagnosed before 1995 & 8 & 62 & $1.86(0.89-3.89)$ & $2.03(0.97-4.23)$ \\
\hline HIV diagnosed after 1995 at index date & 9 & 18 & $5.55(2.49-12.35)$ & $6.31(2.82-14.08)$ \\
\hline Current or previous smoker**** & 15 & 36 & $4.25(2.33-7.75)$ & $4.34(2.43-8.09)$ \\
\hline Never smoked***** & 2 & 10 & $1.98(0.43-9.04)$ & $* * *$ \\
\hline \multicolumn{5}{|l|}{ Route of HIV infection } \\
\hline Men who have sex with men (MSM) & 6 & 52 & $1.52(0.65-3.54)$ & $1.64(0.70-3.82)$ \\
\hline Heterosexually infected men & 5 & 13 & $4.66(1.66-13.10)$ & $5.54(1.96-15.66)$ \\
\hline Heterosexually infected women & I & I & $10.86(0.68-173.30)$ & $* *$ \\
\hline Injection drug user (IDU) & 3 & 8 & $6.95(1.82-26.44)$ & $7.82(2.03-30.16)$ \\
\hline $\begin{array}{l}\text { Baseline CD } 4<350 \text { cells } / \mu \mathrm{L} \text { or } \\
\text { AIDS defining event at index date }\end{array}$ & 10 & 43 & $3.42(|.7|-6.8 \mid)$ & $3.89(1.95-7.78)$ \\
\hline $\begin{array}{l}\text { Baseline CD4 } \geq 350 \text { cells } / \mu \mathrm{L} \text { and } \\
\text { no AIDS defining event at index date }\end{array}$ & 7 & 37 & $2.16(.96-4.85)$ & $2.20(0.97-4.93)$ \\
\hline Head and neck cancer origin & $\begin{array}{l}\text { HIV patients diagnosed } \\
\text { with head and neck } \\
\text { cancer, } \mathrm{N}\end{array}$ & $\begin{array}{l}\text { Population controls } \\
\text { diagnosed with head } \\
\text { and neck cancer, } \mathbf{N}\end{array}$ & $\begin{array}{l}\text { Unadjusted IRR } \\
(95 \% \mathrm{CI})\end{array}$ & $\begin{array}{l}\text { Adjusted IRR* } \\
(95 \% \mathrm{Cl})\end{array}$ \\
\hline Head and neck squamous cell cancers & 16 & 70 & $2.96(I .7 I-5.09)$ & $2.96(1.72-5.09)$ \\
\hline RR for HPV-related HNC & 6 & 16 & $4.66(2.08-10.44)$ & $5.10(2.28-11.44)$ \\
\hline RR for potentially HPV-related HNC & 7 & 42 & $2.75(1.51-5.01)$ & $2.95(1.62-5.37)$ \\
\hline RR for potentially HPV-unrelated HNC & 3 & 12 & $4.49(1.90-10.64)$ & $4.92(2.07-11.66)$ \\
\hline
\end{tabular}

Notes: *In the stratified analyses HIV patients and their respective population controls were included; **all adjusted for gender and age, except the stratification on male which is only adjusted for age and age $>50$ years which is only adjusted for gender; ***too few events for analysis; ****HIV patients (I395) and population controls (I3,950) with missing data on smoking were excluded from this analysis.

Abbreviations: $\mathrm{Cl}$, confidence interval; $\mathrm{HNC}$, head and neck cancer; HPV, human papilloma virus; RR, relative risk.

HIV infected MSMs in our study had a considerably lower and nonsignificant risk of HNC than the heterosexually infected HIV patients, corresponding to the findings of Chaturvedi et al. ${ }^{27}$ This implies that risk factors other than sexual behavior are involved in HIV patients. The consumption of tobacco is higher in persons with lower socioeconomic status and the only study made on the subject in a European setting shows a lower socioeconomic status in heterosexually infected HIV patients than in MSMs. ${ }^{28}$ Therefore the differences could be due to differences in tobacco and alcohol consumption.

Table 3 Characteristics of parents of HIV patients and population controls

\begin{tabular}{|c|c|c|c|c|}
\hline & $\begin{array}{l}\text { Fathers of HIV } \\
\text { patients, } \mathbf{N}(\%)\end{array}$ & $\begin{array}{l}\text { Fathers of population } \\
\text { controls, } \mathbf{N}(\%)\end{array}$ & $\begin{array}{l}\text { Mothers of HIV } \\
\text { patients, N (\%) }\end{array}$ & $\begin{array}{l}\text { Mothers of population } \\
\text { controls, } \mathbf{N}(\%)\end{array}$ \\
\hline All & 2317 & 30,886 & 2502 & 31,928 \\
\hline Median age at index date, years (IQR) & $42.5(40.0-50.1)$ & $41.5(40.0-49.0)$ & $39.1(32.8-46.0)$ & $38.4(32.3-45.2)$ \\
\hline Follow-up time, median, years (IQR) & $23.8(16.4-30.0)$ & $24.5(18.0-30.1)$ & $24.3(17.5-30.3)$ & $25.0(18.9-30.8)$ \\
\hline Duration of follow-up, person-years & 50,937 & 703,036 & 56,538 & 746,786 \\
\hline Emigration during follow-up, $\mathrm{N}(\%)$ & $231(10)$ & $222(0.7)$ & $23(0.9)$ & $170(0.5)$ \\
\hline Lost to follow-up, N (\%) & $2(0.1)$ & $7(0.0)$ & $2(0.1)$ & I $(0.0)$ \\
\hline Diagnosed with all head and neck cancers, $N(\%)$ & $40(1.7)$ & $309(1.0)$ & $20(0.8)$ & $108(0.3)$ \\
\hline $\begin{array}{l}\text { Median age at diagnose of all head and } \\
\text { neck cancers, years (IQR) }\end{array}$ & $62.4(54.5-68.9)$ & $61.8(55.6-68.0)$ & $59.1(53.5-61.1)$ & $61.1(54.4-67.7)$ \\
\hline
\end{tabular}

Abbreviation: IQR, interquartile range. 

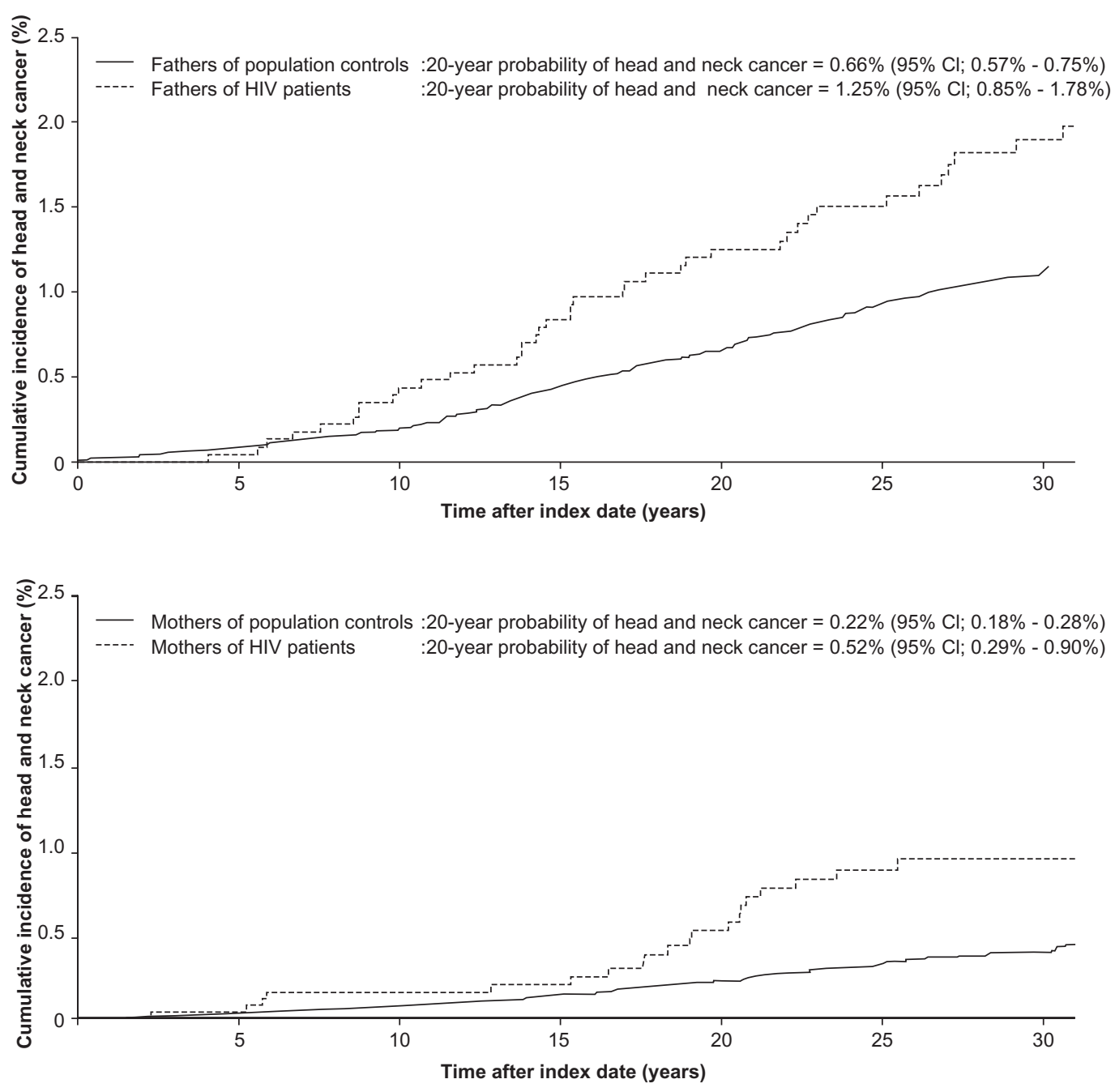

Figure 3 Cumulative incidence function for head and neck cancer among parents of HIV patients and parents of population controls. Abbreviation: $\mathrm{Cl}$, confidence interval.

Table 4 Incidence rate ratios (IRRs, stratified by the offspring's route of HIV infection) for head and neck cancer comparing the parents of HIV patients with the parents of the population controls

\begin{tabular}{|c|c|c|c|c|}
\hline & $\begin{array}{l}\text { Parents of HIV patients } \\
\text { diagnosed with head } \\
\text { and neck cancer, } \mathbf{N}\end{array}$ & $\begin{array}{l}\text { Parents of population } \\
\text { controls diagnosed with } \\
\text { head and neck cancer, } \mathbf{N}\end{array}$ & $\begin{array}{l}\text { Unadjusted IRR } \\
(95 \% \mathrm{CI})\end{array}$ & $\begin{array}{l}\text { Adjusted IRR* } \\
(95 \% \mathrm{Cl})\end{array}$ \\
\hline $\begin{array}{l}\text { Fathers of HIV patients vs fathers } \\
\text { of population controls }\end{array}$ & 40 & 309 & $1.80(1.30-2.50)$ & $1.78(1.28-2.48)$ \\
\hline \multicolumn{5}{|l|}{ Stratification } \\
\hline \multicolumn{5}{|l|}{ Route of HIV infection for offspring } \\
\hline MSM & 23 & 126 & $1.99(1.28-3.11)$ & $1.93(1.24-3.01)$ \\
\hline Heterosexually infected & 6 & 101 & $1.17(0.5 \mathrm{I}-2.67)$ & $1.16(0.51-2.64)$ \\
\hline IDU & 8 & 52 & $2.02(0.96-4.26)$ & $1.99(0.94-4.20)$ \\
\hline Mothers of HIV patients vs & 20 & 108 & $2.47(1.53-3.98)$ & $2.43(1.51-3.92)$ \\
\hline \multicolumn{5}{|l|}{ Mothers of population controls } \\
\hline \multicolumn{5}{|l|}{ Route of HIV infection for offspring } \\
\hline MSM & 10 & 50 & $2.14(1.08-4.21)$ & $2.07(1.05-4.09)$ \\
\hline Heterosexually infected & 2 & 35 & $\mathrm{I} .06(0.26-4.4 \mathrm{I})$ & $1.03(0.25-4.7)$ \\
\hline IDU & 6 & 16 & $4.46(1.79-11.66)$ & $4.42(1.73-11.35)$ \\
\hline
\end{tabular}

Notes: *Adjusted for age at parent index date (continuous variable) as well as year of birth of the parent divided into the following decades: $-1920,1920-1930,1930-1940$, 1940-1950, 1950-later.

Abbreviations: $\mathrm{Cl}$, confidence interval; IDU, injection drug user; MSM, men who have sex with men. 
IDUs with HIV are known to smoke more and did also have an increased risk of lung cancer. ${ }^{29}$

The relative risk of HNC was high among both HIV patients with and without immunodeficiency at baseline but showed no significant difference. Notably the median CD4 cell count at the time of HNC diagnosis was high. This suggests that the increased risk is more likely related to traditional risk factors and there appears to be little association between immunodeficiency and HNC in Danish HIV patients. A similar pattern is seen in cervix cancer in HIV infected women, whereas anal cancer is the only HPV-related cancer in HIV patients in whom a clear association between low CD4 cell count and increased risk has been demonstrated. ${ }^{5,27,30}$

The relative risks of HNC in HIV patients stratified on HPV relation differed little, indicating that the impact of HPV is not higher in Danish HIV patients than in the background population and that risk factors other than immunodeficiency causes the excess risk. Still, we are reluctant to eliminate HIV infection as a direct biological risk factor for HNC, since we were not able to adjust these estimates directly for smoking, alcohol consumption, or HPV status, which are all potential serious confounders.

The risk of HNC was high also in both fathers and mothers of HIV patients, implying that family-associated or behavioral risk factors are involved. However, our study cannot identify the nature of the specific risk factors leading to the increased risk of HNC. Still, risk-taking behavior is moderately to strongly related to heritability and, for example, offspring of smokers have a 4 times higher risk of initiating smoking. ${ }^{31,32}$ More than $70 \%$ of the patients in this HIV cohort were previous or current smokers and HIV patients are shown also to have an excess consumption of alcohol. ${ }^{33}$ It therefore seems likely that their parents share the same risk-taking behavior, which may explain a substantial part of the increased risk of HNC in both HIV patients and their parents. HIV therefore appears to be a marker of familyrelated factors that affect the incidence of HNC. Unlike their offspring and parents of homosexually infected HIV patients, parents of heterosexually infected HIV patients did not have an excess risk of HNC. The effect was consistent for both parent populations, which indicates that this observation is valid. The reason for this is unclear, but the epidemiology of HNC has changed over recent decades and calendar effects may partly explain this phenomenon.

In conclusion both HIV patients and their parents have a high risk of $\mathrm{HNC}$, suggesting that family-related risk factors explain part of the increased risk. None of our stratified or adjusted analyses isolated a single cause of the increased risk of $\mathrm{HNC}$, but smoking, older age, and heterosexual route of infection was associated with an increased risk. HIV appears to be a marker of family-related factors associated with an increased risk of $\mathrm{HNC}$.

\section{Financial support}

The study was financed by The Research Foundation at Copenhagen University Hospital, Rigshospitalet, The Faculty of Health Science, Copenhagen University and NOVO Nordisk Foundation. The funders had no role in the study design; in the collection, management, analysis, and interpretation of data; in the preparation, review, or approval of the manuscript; or in the decision to submit the article for publication. The researchers are independent from the funders.

\section{Acknowledgments}

We thank the staff of our clinical departments for their continuous support and enthusiasm. Centers in The Danish HIV Cohort Study: Departments of Infectious Diseases at Copenhagen University Hospitals, Rigshospitalet (J Gerstoft, N Obel) and Hvidovre (G Kronborg), Odense University Hospital (C Pedersen), Aarhus University Hospitals, Skejby (CS Larsen) and Aalborg (G Pedersen), Herning Hospital (AL Laursen), Helsingør Hospital (L Nielsen) and Kolding Hospital (J Jensen).

\section{Disclosure}

$\mathrm{N}$ Obel has received research funding from Roche, Bristol-Myers Squibb, Merck Sharp and Dohme, GlaxoSmithKline, Abbott, Boehringer Ingelheim, Janssen-Cilag, Swedish Orphan, and NOVO Nordisk Foundation. F Engsig has received research funding from Merck Sharp and Dohme. J Gerstoft has received research funding from Abbott, Roche, Bristol-Myers Squibb, Merck Sharp and Dohme, Pharmasia, GlaxoSmithKline, Swedish Orphan, and Boehringer Ingelheim. $\mathrm{C}$ Pedersen has received funding from Abbott, Roche, BristolMyers Squibb, Merck Sharp and Dohme, GlaxoSmithKline, Swedish Orphan, and Boehringer Ingelheim.

G Kronborg, CS Larsen, and G Pedersen have no conflicts of interest.

\section{References}

1. Lohse N, Hansen AB, Pedersen G, et al. Survival of persons with and without HIV infection in Denmark, 1995-2005. Ann Intern Med. 2007; 146(2):87-95.

2. Engels EA, Biggar RJ, Hall HI, et al. Cancer risk in people infected with human immunodeficiency virus in the United States. Int J Cancer. 2008; 123(1):187-194.

3. Patel P, Hanson DL, Sullivan PS, et al. Incidence of types of cancer among HIV-infected persons compared with the general population in the United States,1992-2003. Ann Intern Med. 2008;148(10):728-736.

4. Silverberg MJ, Chao C, Leyden WA, et al. HIV infection and the risk of cancers with and without a known infectious cause. AIDS. 2009; 23(17):2337-2345. 
5. Shiels MS, Cole SR, Kirk GD, Poole C. A meta-analysis of the incidence of non-AIDS cancers in HIV patients. J Acquir Immune Defic Syndr. 2009;52(5):611-622.

6. Gillison ML, Shah KV. Chapter 9: Role of mucosal human papillomavirus in nongenital cancers. J Natl Cancer Inst Monogr. 2003; 31:57-65.

7. Franceschi S, Munoz N, Bosch XF, Snijders PJ, Walboomers JM. Human papillomavirus and cancers of the upper aerodigestive tract: a review of epidemiological and experimental evidence. Cancer Epidemiol Biomarkers Prev. 1996;5(7):567-575.

8. Dai M, Clifford GM, le CF, et al. Human papillomavirus type 16 and TP53 mutation in oral cancer: matched analysis of the IARC multicenter study. Cancer Res. 2004;64(2):468-471.

9. Schwartz SM, Daling JR, Doody DR, et al. Oral cancer risk in relation to sexual history and evidence of human papillomavirus infection. J Natl Cancer Inst. 1998;90(21):1626-1636.

10. Blot WJ, McLaughlin JK, Winn DM, et al. Smoking and drinking in relation to oral and pharyngeal cancer. Cancer Res. 1988;48(11): 3282-3287.

11. The Central Office of Civil Registration. The Civil Registration System in Denmark;2011. Available online: http://www.cpr.dk/cpr/site. aspx?p=198\&ArticleTypeID=76. Accessed June 3, 2011.

12. Obel N, Engsig FN, Rasmussen LD, Larsen MV, Omland LH, Sorensen HT. Cohort profile: the Danish HIV cohort study. Int $J$ Epidemiol. 2009;38(5):1202-1206.

13. Storm HH, Michelsen EV, Clemmensen IH, Pihl J. The Danish Cancer Registry-history, content, quality and use. Dan Med Bull. 1997;44(5): 535-539.

14. Christensen K, Schmidt MM, Vaeth M, Olsen J. Absence of an environmental effect on the recurrence of facial-cleft defects. $N$ Engl J Med. 1995;333:161-164.

15. NORDCAN. [homepage on the Internet]. The NORDCAN project; 2009 [updated 2010 October 22]. Available from: www-dep.iarc.fr/ NORDCAN. Accessed May 20, 2011.

16. Ryerson AB, Peters ES, Coughlin SS, et al. Burden of potentially human papillomavirus-associated cancers of the oropharynx and oral cavity in the US,1998-2003. Cancer. 2008;113(10 Suppl):2901-2909.

17. Marubini E, Valsecci MG. Analysing Survival Data from Clinical trials and Observational Studies. 1st ed. Chichester, England: John Wiley and Sons; 1995:331-363.

18. Blomberg M, Nielsen A, Munk C, Kjaer SK. Trends in head and neck cancer incidence in Denmark,1978-2007: Focus on human papillomavirus associated sites. Int J Cancer. 2010;September 28. [Epub ahead of print].

19. Kjøller M. The Public Health Report Denmark 2007. National Institute of Public Health; 2007. Available online: http:/www.si-folkesundhed. dk/Udgivelser/B\%C3\%B8ger\%20og\%20rapporter/2008/2897\%20 Folkesundhedsrapporten\%202007.aspx. Accessed June 3, 2011.
20. Smith EM, Ritchie JM, Summersgill KF, et al. Age, sexual behavior and human papillomavirus infection in oral cavity and oropharyngeal cancers. Int J Cancer. 2004;108(5):766-772.

21. Gillison ML, D'Souza G, Westra W, et al. Distinct risk factor profiles for human papillomavirus type 16-positive and human papillomavirus type 16-negative head and neck cancers. J Natl Cancer Inst. 2008; 100(6):407-420.

22. Herrero R, Castellsague X, Pawlita M, et al. Human papillomavirus and oral cancer: the International Agency for Research on Cancer multicenter study. J Natl Cancer Inst. 2003;95(23):1772-1783.

23. Furniss CS, McClean MD, Smith JF, et al. Human papillomavirus 16 and head and neck squamous cell carcinoma. Int J Cancer. 2007; 120(11):2386-2392.

24. Weinberger PM, Yu Z, Haffty BG, et al. Molecular classification identifies a subset of human papillomavirus-associated oropharyngeal cancers with favorable prognosis. J Clin Oncol. 2006;24(5):736-747.

25. Schwartz SR, Yueh B, McDougall JK, Daling JR, Schwartz SM. Human papillomavirus infection and survival in oral squamous cell cancer: a population-based study. Otolaryngol Head Neck Surg. 2001; 125(1):1-9.

26. Heck JE, Berthiller J, Vaccarella S, et al. Sexual behaviours and the risk of head and neck cancers: a pooled analysis in the International Head and Neck Cancer Epidemiology (INHANCE) consortium. Int $J$ Epidemiol. 2010;39(1):166-181.

27. Chaturvedi AK, Madeleine MM, Biggar RJ, Engels EA. Risk of human papillomavirus-associated cancers among persons with AIDS. J Natl Cancer Inst. 2009;101(16):1120-1130.

28. Rapiti E, Porta D, Forastiere F, Fusco D, Perucci CA. Socioeconomic status and survival of persons with AIDS before and after the introduction of highly active antiretroviral therapy. Lazio AIDS Surveillance Collaborative Group. Epidemiology. 2000;11(5):496-501.

29. Marshall MM, Kirk GD, Caporaso NE, et al. Tobacco use and nicotine dependence among HIV-infected and uninfected injection drug users. Addict Behav. 2010;36(1-2):61-67.

30. Guiguet M, Boue F, Cadranel J, Lang JM, Rosenthal E, Costagliola D. Effect of immunodeficiency, HIVviral load, and antiretroviral therapy on the risk of individual malignancies (FHDH-ANRS CO4): a prospective cohort study. Lancet Oncol. 2009;10(12):1152-1159.

31. Zuckerman M, Kuhlman DM. Personality and risk-taking: common bisocial factors. J Pers. 2010;68(6):999-1029.

32. den Exter Blokland EA, Engels RC, Hale WW III, Meeus W, Willemsen MC. Lifetime parental smoking history and cessation and early adolescent smoking behavior. Prev Med. 2004;38(3):359-368.

33. Friis-Moller N, Weber R, Reiss P, et al. Cardiovascular disease risk factors in HIV patients-association with antiretroviral therapy. Results from the DAD study. AIDS. 2003;17(8):1179-1193. 


\section{Appendix}

Cancers included as competing risk in the study were coded according to The International Classification of Diseases (ICD) version 10 in the period 1978-2007: Lib cancer (ICD-10; C00), Tongue cancer (ICD-10; C01-C02), Oral cavity cancer (ICD-10; C03-C06), Salivary glands cancer (ICD-10; C07-C08), Tonsil cancer (ICD-10; C09), Pharynx cancer (1470-1480, ICD-10; C10-C14), Sinuses, nasal cavity and middle ear (ICD-10; C30), Larynx cancer (ICD-10; C32), Trachea cancer (2620, ICD-10; C33), Pleura cancer (ICD-10; C38.4, C45), Oesophagus, stomach and small intestine cancer (ICD-10; C15-C17), Colon cancer (ICD-10; C18-C20),
Anal cancer (ICD-10; C21), Pancreas cancer (ICD-10; C25), Liver cancer (ICD-10; C22), Biliary tract cancer (ICD-10; C23, C24), Lymphoid cancer (ICD-10; C81-C85, C90-C96), Urinary tract cancers (ICD-10; C64-C68, D90, D414), Skin cancer (ICD-10; C43, C46), Bone, articular cartilage, mesothelial, and soft tissue cancer (ICD-10; C40, C41, C46.1 C49), Breast cancer (ICD-10; C50), Female genital cancer (ICD-10; C51-C58), Eye, brain, and other parts of the central nervous system (ICD-10; C69-C72, D32, D34, D42, D43), Male genital organs (ICD-10; C60-C63), Thyroid and other endocrine organs (ICD-10; C73-C75), Kaposi sarcoma (ICD-10; C46).
Clinical Epidemiology

\section{Publish your work in this journal}

Clinical Epidemiology is an international, peer-reviewed, open access journal focusing on disease and drug epidemiology, identification of risk factors and screening procedures to develop optimal preventative initiatives and programs. Specific topics include: diagnosis, prognosis, treatment, screening, prevention, risk factor modification, systematic

\section{Dovepress}

reviews, risk \& safety of medical interventions, epidemiology \& biostatical methods, evaluation of guidelines, translational medicine, health policies \& economic evaluations. The manuscript management system is completely online and includes a very quick and fair peer-review system, which is all easy to use. 